\title{
Colloidal stability of gadolinium-doped ceria powder in aqueous and non-aqueous media
}

\author{
${ }^{*}$ Corresponding author: Dr. Manuel-Jesús López Robledo \\ Instituto de Ciencia de los Materiales de Aragón (ICMA) \\ CSIC-Universidad de Zaragoza (Facultad de Ciencias) \\ C/ Pedro Cerbuna $n^{\circ} 12$ - 50009 Zaragoza, Spain \\ Email ID: robledo@unizar.es \\ Phone No.: +34976 7610 00, ext. 3496; \\ Fax: +34976762453
}

M.J. López-Robledo ${ }^{a, *}$, J. Silva-Treviño ${ }^{a}$, T. Molina $^{b}$, R. Moreno ${ }^{b}$

(a) Instituto de Ciencia de los Materiales de Aragón (CSIC-Universidad de Zaragoza), c/Pedro Cerbuna $n^{\circ}$ 12, 50009 Zaragoza, Spain (b) Instituto de Cerámica y Vidrio (CSIC), c/Kelsen n 5, Cantoblanco, 28049 Madrid, Spain

\section{Abstract}

In this work the colloidal behaviour of $\mathrm{Ce}_{0.9} \mathrm{Gd}_{0.1} \mathrm{O}_{2-\delta}$ powder in aqueous and nonaqueous media (ethanol) is studied. Commercial powder was characterised by particle size distribution, specific surface area measurements, X-ray diffraction and scanning electron microscopy. Diluted suspensions were characterised by particle size distribution and zeta potential, using dynamic light scattering and laser Doppler velocimetry principles, respectively. The solubility of the powder in water as a function of $\mathrm{pH}$ was analysed by inductively coupled plasma atomic emission spectrometry. Colloidal stability was studied as a function of $\mathrm{pH}$, type and concentration of dispersants (polyacrylic-based deflocculant in water and a phosphate ester in ethanol). The time stability of the suspensions was analyzed by multiple light scattering. The most stable suspension was obtained with a phosphate ester content of $2.0 \mathrm{wt} \%$ in ethanol. Finally, preliminary coatings have been obtained by dip coating using concentrated suspensions, which could be accessible to industrial scale so that they can be used as interlayers in solid oxide fuel cells.

Keywords: Suspensions; Zeta potential; Colloidal behaviour; $\mathrm{Ce}_{0.9} \mathrm{Gd}_{0.1} \mathrm{O}_{2-\delta}$; Fuel cells 


\section{Introduction}

Solid oxide fuel cells (SOFC) are one of the most promising alternatives to convert chemical energy into electricity, due to its high conversion efficiency, low emission of pollutants and the useful fuels flexibility [1].

Nowadays, research into new materials and new processes of fabrication related to fuel cell development aims to minimize the number of processing steps and improve fuel cell performance at lower operating temperatures [2]. In practical applications, gadolinium doped ceria $\left(\mathrm{Ce}_{0.9} \mathrm{Gd}_{0.1} \mathrm{O}_{2-\delta}, \mathrm{GDC}\right)$ interlayers are used as diffusion barrier layer to prevent thermochemical incompatibility between the cathode with perovskite structure $\mathrm{La}_{1-x} \mathrm{Sr}_{x} \mathrm{Co}_{1-y} \mathrm{Fe}_{y} \mathrm{O}_{3-\delta}$ (LSCF) and traditional electrolyte of yttria-stabilized zirconia (YSZ) in 2.5G generation anodesupported cells [2-20]. Furthermore, GDC is focused as an alternative to YSZ as electrolyte in fuel cells at intermediate temperatures IT-SOFC [17] due to its high ionic conductivity at $600^{\circ} \mathrm{C}$.

Although GDC has been used in various conventional ceramic powder techniques, a critical problem arises from its poor sinterability. It is highly refractory and exhibits a high melting point $\left(2300^{\circ} \mathrm{C}\right)$, which inhibits densification even at temperatures above $1600^{\circ} \mathrm{C}$. As a result of this, most interlayers presented in literature are porous [5-12,18-20]. Therefore, more reactive powders are needed, but the use of nanopowders leads to higher agglomeration and hence to grain coarsening and sintering defects $[19,20]$. A better microstructural uniformity can be achieved if agglomerates are avoided by maintaining particles far apart through the manipulation of interparticle forces. This can be achieved using stable colloidal suspensions, where the repulsive forces are enabled by the use of dispersants. Indeed, colloidal processing allows the control of the early steps of powder processing and its evolution during forming and consolidation steps [21].

A goal is to optimize the suspension performance in order to produce homogeneous thin GDC layers with controlled thickness and porosity, which could be easily scaled-up to an 
industrial scale. A major limitation is the poor sinterability of the GDC powder which makes it difficult to obtain such controlled dense layers. However, colloid chemistry can provide an excellent approach to produce dense coatings by conventional processing routes combining the consolidation of well-dispersed particles and further sintering step. As a first step, the manufacture of GDC coatings with controlled porosity can be also of interest for other applications, such as anti-pollution barriers. Therefore, more work is necessary to improve its performance.

The aim of this work was to study the colloidal behaviour of GDC powders in aqueous and non-aqueous media in terms of particle size distribution, zeta potential, and the study of physical destabilisation of the suspensions using the multiple light scattering (MLS) technique. The effect of deflocculants nature and concentration in the suspensions stability is also described.

\section{Experimental}

\subsection{Characterisation of starting powders}

A commercial gadolinium doped ceria $\mathrm{Ce}_{0.9} \mathrm{Gd}_{0.1} \mathrm{O}_{2-\delta}$ powder (Fuel Cells Materials, USA), was employed as starting material. According to the supplier this powder has an average particle size between 0.3-0.4 $\mu \mathrm{m}$ and specific surface area between $30-40 \mathrm{~m}^{2} / \mathrm{g}$.

Starting powders were characterised by particle size measurements (Mastersizer $S$, Malvern, UK), specific surface area using the single point BET method (Monosorb Surface Area Analyser MS-13, Quantachrome, USA), microstructure by field-emission scanning electron microscopy (Merlin FE-SEM, Carl Zeiss, Germany) and crystalline phases by X-ray diffraction (Siemens D-5000, Germany). The BET particle size was calculated by specific surface area measurements, assuming spherical, homogeneous primary particles, through the following equation 


$$
d_{B E T}=6 \rho / S_{B E T}
$$

where $S_{B E T}$ is the measured specific surface and $\rho$ is the material density. The obtained values were $S_{B E T}=34 \pm 2 \mathrm{~m}^{2} / \mathrm{g}$ and $d_{B E T}=1.2 \pm 0.1 \mu \mathrm{m}$.

The particle size distribution was determined by the diffraction method with a $\mathrm{He}-\mathrm{Ne}$ laser $(\lambda=632.8 \mathrm{~nm})$ on wet sample. Distilled water with deflocculant (Dolapix Ce-64) was used, facilitating the dispersion of powders in an ultrasonic bath for 5 minutes. The measured particle size distributions of GDC powders before and after sonication are shown in Fig. 1. The bimodal curve shown in the graph indicates that the powder is agglomerated initially, and after application of ultrasounds agglomerates break down and a nearly Gaussian curve is obtained. An average size of $1 \mu \mathrm{m}$ was measured, similar to $d_{B E T}$ value calculated previously.

\subsection{Characterisation of suspensions}

After characterising the dry GDC powders, the colloidal behaviour of suspensions prepared in water and ethanol was studied.

Before the colloidal behaviour, the solubility of the powders in water as a function of $\mathrm{pH}$ was studied. Suspensions were prepared in water at different $\mathrm{pH}$ values, left a stabilisation time and further centrifuged at $2400 \mathrm{rpm}$. The supernatant was analysed by inductively coupled plasma atomic emission spectrometry (ICP-AES), conducted on an IRIS Advantage (Thermo Jarrell Ash, USA) spectrometer, to determine the concentration of Ce or Gd dissolved in the supernatant.

The stability against $\mathrm{pH}$ was studied by zeta-potential measurements in order to determine the isoelectric point (IEP). For these measurements, dispersions of GDC powders were prepared to $0.1 \mathrm{~g} / \mathrm{l}$ solid content in a solution of $\mathrm{KCl} 10^{-2} \mathrm{M}$, as inert electrolyte. The $\mathrm{pH}$ was measured with a pH-meter (Titrino DMS 716, Metrohm, Switzerland) and was adjusted using $\mathrm{HCl}\left(10^{-1} \mathrm{M}\right)$ and $\mathrm{KOH}\left(10^{-1} \mathrm{M}\right)$ at room temperature. Suspensions were stirred for $24 \mathrm{~h}$ 
prior to measurements in order to reach surface equilibrium. An ammonium salt of a polyacrylic acid PAA (Duramax-D3005, Rohm\&Hass, PA, USA) was used as a polyelectrolyte to provide electrosteric stabilisation at moderate $\mathrm{pH}$ value. Deflocculant concentrations of $0,0.5,1.5,2.0$, and $3.0 \mathrm{wt} \%$ (with respect to the GDC total mass) were studied. All suspensions were prepared using an ultrasounds probe (UP 400S dr.hielscher $\mathrm{GmbH}$, Germany) for homogenisation.

\section{Zeta potential ( $\zeta$ ) was measured by Laser Doppler Velocimetry technique (Zetasizer} NanoZS, Malvern, UK) and applying the Henry equation:

$$
U_{E}=2 \varepsilon \zeta f(k a) / 3 \eta
$$

where $\zeta$ is the zeta potential, $U_{E}$ the electrophoretic mobility, $\varepsilon$ the dielectric constant of water, $\eta$ the medium viscosity and $f(k a)$ is the Henry's function. Calculations of the mobility were done considering the Smoluchowski approximation $(f(k a)=1.5)$.

The tendency to agglomeration was evaluated measuring the particle size distribution of dilute aqueous suspensions by dynamic light scattering principle, using the same instrument used for zeta potential determinations.

Non-aqueous suspensions of GDC were prepared in ethanol absolute PRS (Panreac, Spain). A phosphate ester deflocculant Beycostat-C213 (CECA, France) was used to provide electrosteric stabilisation. The colloidal stability was studied through zeta potential measurements as a function of dispersant contents. Dispersant concentrations of $0,0.5,1.5$, and 2.0 wt\% (with respect to the GDC total mass) were studied.

The physical destabilisation of the suspensions against time was evaluated by measuring the settling behaviour using the multiple light scattering (MLS) technique (Turbiscan Lab Expert, Formulaction, France), in which a pulsed near-infrared light source with a wavelength of $850 \mathrm{~nm}$ is forced to pass through a suspension maintained at rest into a glass tube. In references 22 and 23 is detailed at length the measuring principles and main applications of this technique are described in depth. A major advantage of MLS as compared 
to other optical techniques such as microscopy, laser diffraction or dynamic light scattering, is that the former is non-destructive as no sample dilution is needed. The instrument is able to detect particle size variation or particle migration in concentrated and optical thick media. The amount of suspension needed for the MLS measurement is very low $(4-8 \mathrm{ml})$.

The possibility of determining the evolution of these suspensions with time in the stationary state could provide important additional information about the actual behaviour of the suspension, regarding the formation of a particle structure (i.e. the particle forces). During the MLS tests the transmission detector collects the light that passes through the sample and the backscattering one the backward scattered light. The suspensions were prepared to $1 \mathrm{~g} / \mathrm{l}$ solid content in $\mathrm{H}_{2} \mathrm{O}$, in ethanol, in $\mathrm{H}_{2} \mathrm{O}$ with 3.0 wt\% of Duramax-D3005 and in ethanol with 2.0 wt\% of Beycostat-C213 were introduced in the measuring cell and the backscattering and transmission signals were registered every minute up to $2 \mathrm{~h}$.

Finally, concentrated suspensions for dip-coating (9-20 vol.\% solids) were prepared by mixing the GDC powder, solvents (ethanol), binder (polyvinyl butyral) and dispersant (phosphate ester). Using a dip-coating apparatus constructed in our laboratory, NiO-YSZ/YSZ tubes were dipped in the slurries and coated at the pulling rate within the range of $1.5-3.0 \mathrm{~mm} / \mathrm{s}$. The coated films were dried in air and sintered between 1300 and $1450{ }^{\circ} \mathrm{C}$ for $2 \mathrm{~h}$ in air. These preliminary coatings were studied by field-emission scanning electron microscopy (Merlin FESEM, Carl Zeiss, Germany).

\section{Results and discussion}

\subsection{Characterisation of starting powders}

X-ray diffraction (XRD) patterns of the GDC powders are shown in Fig. 2. It can be noted that the XRD pattern shows high crystallinity and fits the pattern $\mathrm{Ce}_{0.9} \mathrm{Gd}_{1.0} \mathrm{O}_{1.95}(75-0161$, JCPDS - International Centre for Diffraction Data, 2000). From the Scherrer formula (3), the average size of the crystallites that define the XRD pattern was estimated to be $18 \pm 1 \mathrm{~nm}$. 
where $t$ is the size of the crystallites in Armstrong, $F$ the form factor (use 0.9), $\lambda$ the wavelength as $\AA, B$ the width measured at half height of peak $B$ (in radians) and $\theta_{B}$ the selected angle of the main peak.

Microstructural observations made by FE-SEM, (Fig. 3) show that commercial powders are formed by weak agglomerates of sub-micron sized particles with flake shape.

\subsection{Characterisation of suspensions}

\subsubsection{Dispersion studies}

Prior to colloidal stability studies, the solubility of the powders in water at different $\mathrm{pHs}$ was determined. Fig. 4 shows the concentration of free $\mathrm{Ce}$ and $\mathrm{Gd}$ as a function of $\mathrm{pH}$. As it can be seen the maximum stability is achieved at neutral $\mathrm{pH}$ values, whereas solubilisation occurs at either acidic or alkaline $\mathrm{pHs}$.

In Fig. 5 the zeta potential values measured for GDC powders in water as a function of $\mathrm{pH}$ are plotted. The natural $\mathrm{pH}$ was 5.9 with a zeta potential of $+19 \mathrm{mV}$. The measured IEP occurs at about $\mathrm{pH} 7.0$, and for $\mathrm{pH}$ values between 7 and 12 there is a rapid decrease of the zeta potential. Stable suspensions can be prepared at $\mathrm{pH}<5$ or at $\mathrm{pH}>9$, where absolute values of zeta potential are high enough to provide stability. However, at these $\mathrm{pHs}$ values solubilisation occurs, as demonstrated above, so that the dispersion with a polyelectrolyte is necessary to shift the isoelectric point toward low $\mathrm{pH}$ to maintain high stability at neutral values.

At the same time, the particle sizes of the different suspensions were determined. As it can be observed in fig. 6, particle size maintains nearly constant with $\mathrm{pH}$ until a strong basic media is reached, where the large increase of ionic concentration makes the double layer to 
comprise. As a consequence, thinner double layers are not enough to maintain stability and agglomeration occurs.

The stability of the suspensions as a function of polyelectrolyte concentration was studied with measurements of zeta potential (Fig. 7). A maximum zeta potential of $-51 \mathrm{mV}$ was obtained for $3.0 \mathrm{wt} \%$ polyelectrolyte. For this reason, this was selected as the best deflocculant concentration in aqueous medium. It was observed too that the $\mathrm{pH}$ slightly increased from 5.8 to 6.0 as the deflocculant content increased from 0 to $3.0 \mathrm{wt} \%$. This demonstrates that specific adsorption occurs and the isoelectric point shifts down to lower $\mathrm{pH}$ values.

Similarly, the stability of suspensions prepared in organic medium was studied. The variation of zeta potential as a function of dispersant content is plotted in Fig. 8. All suspensions in ethanol had a positive zeta potential. The best dispersing conditions were achieved for $2 \mathrm{wt} \%$ of Beycostat-C213, which had the largest value of zeta potential $(+34 \mathrm{mV})$.

\subsubsection{Stability against time}

The two major destabilisation phenomena are related to particle migration (creaming, sedimentation) and aggregation (coalescence, flocculation). Both of them have been studied using the MLS technique. Fig. 9 shows the evolution of the backscattering measurements through the cell every minute up to $2 \mathrm{~h}$. The analysis for each suspension is as follows:

In $\mathrm{H}_{2} \mathrm{O}$ : at the bottom of the cell (cap) the backscattering strongly increases. At the top of the cell (meniscus) the backscattering decreases with time due to the clarification of the suspension as settling takes place. Both results indicate the formation of a sedimentation front.

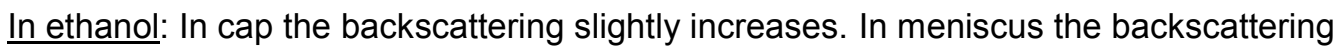
decreases with time. Both results indicate the formation of a solidification front, but slower than in water. This suspension is thus more stable. 


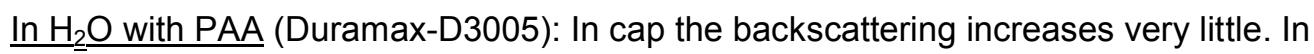
meniscus the backscattering strongly increases. Both results indicate a slight formation of solidification front, and creaming occurs too.

In ethanol with phosphate ester (Beycostat-C213): In both zones a regular profile is observed, meaning that the suspension is more stable, which is consistent with the results of dispersion studies.

The transmittance data obtained during sedimentation tests with the MLS technique have been used to estimate the sedimentation rate of each suspension. The obtained values are reported in Table 1.

Fig. 10 shows clarification measurements versus time. The suspension in ethanol with phosphate ester presents the largest stability over time, as demonstrated by the lower sedimentation rate.

\subsection{Preliminary coatings tests}

Once the optimum stability for dilute GDC suspensions has been established, a more detailed study of concentrated suspensions in ethanol has been performed, considering the effect of the most important processing parameters on coating performance, including the solids loading, the binder concentration, the sintering temperature, etc. This preliminary study has allowed us to improve ceramic slurry performance to produce GDC layers of controlled thickness and porosity, with good adhesion to the substrate, and an acceptable density to achieve the sintering process to take place. The results of these coating tests demonstrate that it is possible to produce a relative dense GDC layers that could be successfully used as buffer layer between YSZ electrolyte and catalytically active cathode layers, or as electrolyte in solid oxide fuel cells. Fig. 11 shows GDC coatings deposited onto YSZ electrolyte by dip coating and how thin permeable layers are obtained. 


\section{Conclusions}

The colloidal behaviour of commercial powder of gadolinum doped ceria in water and ethanol has been studied. Microstructural observations demonstrate that the particles are agglomerated forming irregular granules of several dimensions and shapes. Indeed, XRD confirms that powders is crystalline and shows that the primary particles have an average size of $18 \pm 1 \mathrm{~nm}$.

The variation of zeta potential of commercial powders dispersed in water and ethanol, with different concentrations of dispersants has been studied. The isoelectric point of these powders occurs at neutral $\mathrm{pH}$ values about 7 . The chemical analysis of the supernatant liquid of centrifuged suspensions demonstrates that at neutral $\mathrm{pH}$ there are no dissolved species in the liquid, so that the use of a polyelectrolyte is required to shift the isoelectric point and to maintain the suspension stability at neutral pH. 3.0 wt $\%$ of PAA (Duramax-D3005) was selected as the best deflocculant concentration in aqueous medium, and $2.0 \mathrm{wt} \%$ of phosphate ester (Beycostat-C213) in ethanol.

The physical destabilisation of the suspensions against time was evaluated by measuring the settling behaviour using the multiple light technique scattering. The suspension prepared in ethanol with deflocculant (2.0 wt\% Beycostat-C213) maintains high stability over time.

Homogeneous, relatively dense coatings with the desired thickness have been successfully obtained by dip coating after preliminary tests using concentrated GDC suspensions dispersed with $2.0 \mathrm{wt} \%$ of Beycostat-C213 and $2.5 \mathrm{wt} \%$ of polyvinyl butyral in ethanol, which opens the possibility to obtain thicker and denser coatings by colloidal processing.

\section{Acknowledgements}


We would like to thank grants PSE-120000-2008-0040 and MAT2009-14324-C02-01, financed by the Spanish Government (Ministerio de Ciencia e Innovación) and Feder program of the European Community, and PI/116, financed by the Aragón Government.

\section{References}

[1] Singhal SC, Kendall K. High Temperature Solid Oxide Fuel Cells: Fundamental, Design and Applications. Oxford: Elsevier; 2003.

[2] Christiansen N, Holm-Larsen H, Primdahl S, Wandel M, Ramousse S, Hagen A. Recent Progress in Development and Manufacturing of SOFC at Topsoe Fuel Cell A/S and Risø DTU. ECS Trans. 2011;35:71-80.

[3] Uchida H, Arisaka S, Watanabe M. High performance electrode for medium-temperature solid oxide fuel cells. $\mathrm{La}(\mathrm{Sr}) \mathrm{CoO}_{3}$ cathode with ceria interlayer on zirconia electrolyte. Electrochem. Solid State Lett. 1999;2:428-430.

[4] Simner SP, Bonnett JR, Canfield NL, Meinhardt KD, Shelton JP, Sprenkle VL, Stevenson JW. Development of lanthanum ferrite SOFC cathodes. J. Power Sources 2003;113:1-10. [5] Nguyen TL, Kobayashi K, Honda T, limura Y, Kato K, Neghisi A, Nozaki K, Tappero F, Sasaki K, Shirahama H, Ota K, Dokiya M, Kato T. Preparation and evaluation of doped ceria interlayer on supported stabilized zirconia electrolyte SOFCs by wet ceramic processes. Solid State lonics 2004;174:163-174.

[6] Shiono M, Kobayashi K, Nguyen TL, Hosoda K, Kato T, Ota K, Dokiya M. Effect of $\mathrm{CeO}_{2}$ interlayer on $\mathrm{ZrO}_{2}$ electrolyte/La( $\left.\mathrm{Sr}\right) \mathrm{CoO}_{3}$ cathode for low-temperature SOFCs. Solid State Ionics $2004 ; 170: 1-7$.

[7] Mai A, Haanappel VAC, Uhlenbruck S, Tietz F, Stöver D. Ferrite-based perovskites as cathode materials for anode-supported solid oxide fuel cells. Solid State lonics 2005;176:13411350.

[8] Mai A, Haanappel VAC, Tietz F, Stöver D. Ferrite-based perovskites as cathode materials for anode-supported solid oxide fuel cells. Part II. Influence of the CGO interlayer. Solid State Ionics 2006;177:2103-2107.

[9] Wang ZR, Qian JQ, Wang SR, Cao JD, Wen TL. Improvement of anode-supported solid 
oxide fuel cells. Solid State Ionics 2008;179:1593-1596.

[10] Uhlenbruck S, Jordan N, Sebold D, Buchkremer HP, Haanappel VAC, Stöver D. Thin film coating technologies of $(\mathrm{Ce}, \mathrm{Gd}) \mathrm{O}_{2-\delta}$ interlayers for application in ceramic high-temperature fuel cells. Thin Solid Films 2007;515:4053-4060.

[11] Jordan N, Assenmacher W, Uhlenbruck S, Haanappel VAC, Buchkremer HP, Stover D, Mader W. $\mathrm{Ce}_{0.8} \mathrm{Gd}_{0.2} \mathrm{O}_{2-\delta}$ protecting layers manufactured by physical vapour deposition for ITSOFC. Solid State Ionics 2008;179:919-923.

[12] Uhlenbruck S, Moskalewicz T, Jordan N, Penkalla HJ, Buchkremer HP. Element interdiffusion at electrolyte-cathode interfaces in ceramic high-temperature fuel cells. Solid State lonics 2009;180:418-423.

[13] Fonseca FC, Uhlenbruck S, Nedelec R, Buchkremer HP. Properties of bias-assisted sputtered gadolinia-doped ceria interlayers for solid oxide fuel cells. J. Power Sources 2010;195:1599-1604.

[14] Lu ZG, Zhou XD, Fisher D, Templeton J, Stevenson J, Wu NJ, Ignatiev A. Enhanced performance of an anode-supported YSZ thin electrolyte fuel cell with a laser-deposited $\mathrm{Sm}_{0.2} \mathrm{Ce}_{0.8} \mathrm{O}_{1.9}$ interlayer. Electrochem. Commun. 2010;12:179-182.

[15] Knibbe R, Hjelm J, Menon M, Pryds N, Søgaard M, Wang HJ, Neufeld K. CathodeElectrolyte Interfaces with CGO Barrier Layers in SOFC. J. Am. Ceram. Soc. 2010;93:28772883.

[16] Kostogloudis GC, Tsiniarakis G, Ftikos C. Chemical reactivity of perovskite oxide SOFC cathodes and yttria stabilized zirconia. Solid State lonics 2000;135:529-535.

[17] Steele BCH. Appraisal of $\mathrm{Ce}_{1-y} \mathrm{Gd}_{\mathrm{y}} \mathrm{O}_{2-\mathrm{y} / 2}$ electrolytes for IT-SOFC operation at $500^{\circ} \mathrm{C}$. Solid State lonics 2000;129:95-110.

[18] Wang DF, Wang JX, He CR, Tao YK, Xu C, Wang WG. Preparation of a $\mathrm{Gd}_{0.1} \mathrm{Ce}_{0.9} \mathrm{O}_{2-\delta}$ interlayer for intermediate-temperature solid oxide fuel cells by spray coating. J. Alloys Compd. 2010;505:118-124.

[19] Gong Y, Ji W, Zhang L, Li M, Xie B, Wang H, Jiang Y, Song Y. Low temperature deposited (Ce, Gd) $\mathrm{O}_{2-x}$ interlayer for $\mathrm{La}_{0.6} \mathrm{Sr}_{0.4} \mathrm{Co}_{0.2} \mathrm{Fe}_{0.8} \mathrm{O}_{3}$ cathode based solid oxide fuel cell. J. Power Sources 2011;196:2768-2772.

[20] Gil V, Gurauskis J, Campana R, Merino RI, Larrea A, Orera VM. Anode-supported microtubular cells fabricated with gadolinia-doped ceria nanopowders. J. Power Sources 
2011;196:1184-1190.

[21] Burgos-Montes $\mathrm{O}$, Moreno R. Stability of concentrated suspensions of $\mathrm{Al}_{2} \mathrm{O}_{3}-\mathrm{SiO}_{2}$ measured by multiple light scattering. J. Eur. Ceram. Soc. 2009;29:603-610.

[22] Mengual O, Meunier G, Cayre I, Puech K, Snabre P. TURBISCAN MA 2000: multiple light scattering measurement for concentrated emulsion and suspension instability analysis. Talanta 1999;50:445-456.

[23] Mengual O, Meunier G, Cayre I, Puech K, Snabre P. Characterisation of instability of concentrated dispersions by a new optical analyser: the TURBISCAN MA 1000. Colloids Surf. A $1999 ; 152: 111-123$.

\section{Figure captions}

Fig. 1. Size distribution of GDC powders.

Fig. 2. XRD patterns of the GDC powders.

Fig. 3. FE-SEM images of GDC initial powders without (a) and with (b, c) sonication.

Fig. 4. Concentration of dissolved ions of $\mathrm{Ce}$ and $\mathrm{Gd}$ in suspensions prepared at different $\mathrm{pH}$ values.

Fig. 5. Zeta potential vs. pH of GDC powders in water.

Fig. 6 Particle size vs. pH of GDC powders in aqueous.

Fig. 7. Zeta potential vs. polyelectrolyte concentration for GDC powders in aqueous.

Fig. 8. Zeta potential vs. dispersant content for GDC powders in organic medium.

Fig. 9. Backscattered NIR light registered along the sample with time for GDC powders in aqueous and organic medium, with/without dispersant.

Fig. 10. Clarification values registered with time for GDC powders in aqueous and organic medium, with/without dispersant.

Fig. 11. FE-SEM images of cross-section and the surface of GDC layers onto YSZ electrolyte obtained by dip coating with suspensions at solid loading of 12 vol.\% sintered at $1300^{\circ} \mathrm{C}$ for $2 \mathrm{~h}$ (a,b), and of 15 vol. $\%$ sintered at $1450{ }^{\circ} \mathrm{C}$ for $2 \mathrm{~h}(\mathrm{c}, \mathrm{d})$. 


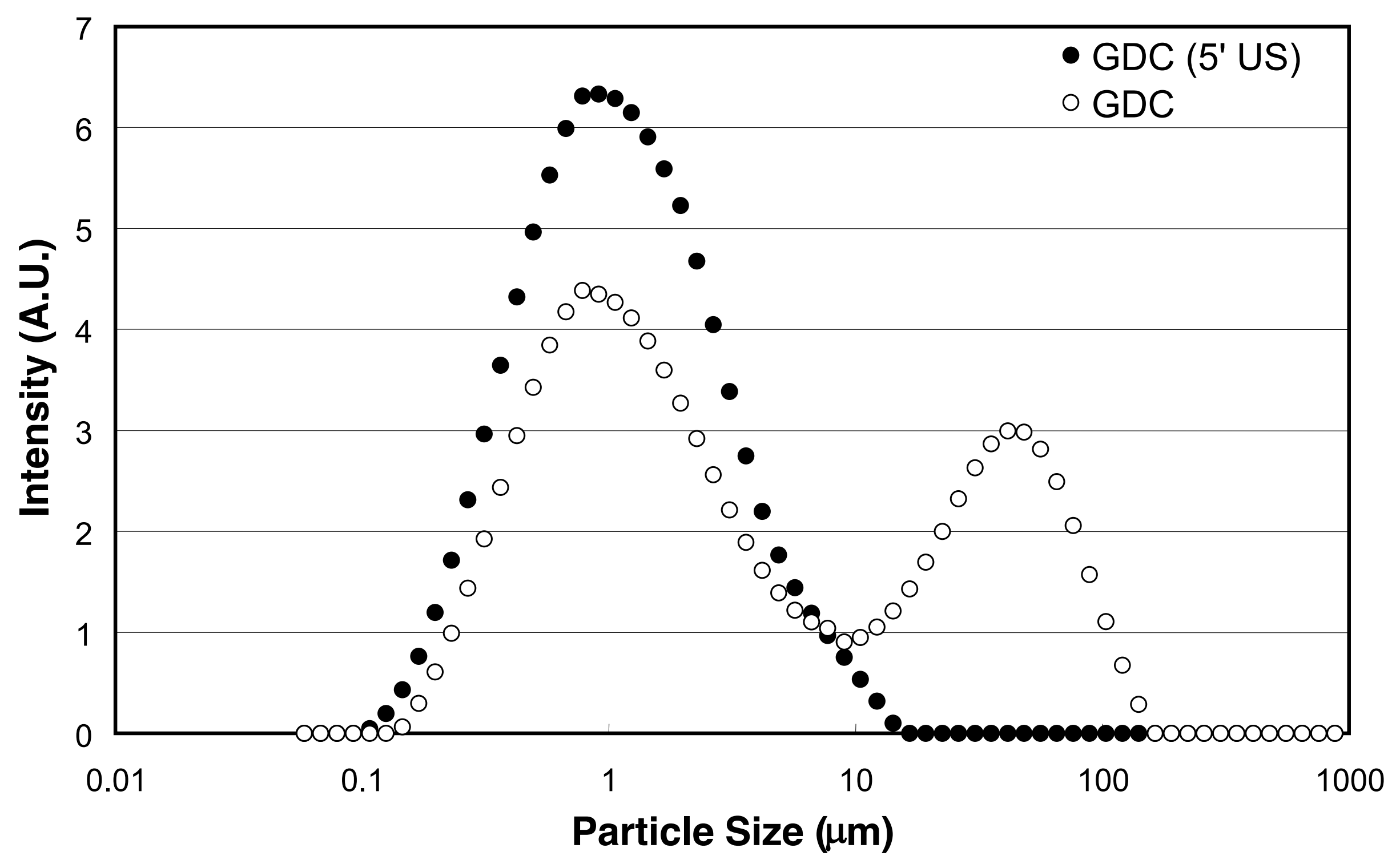




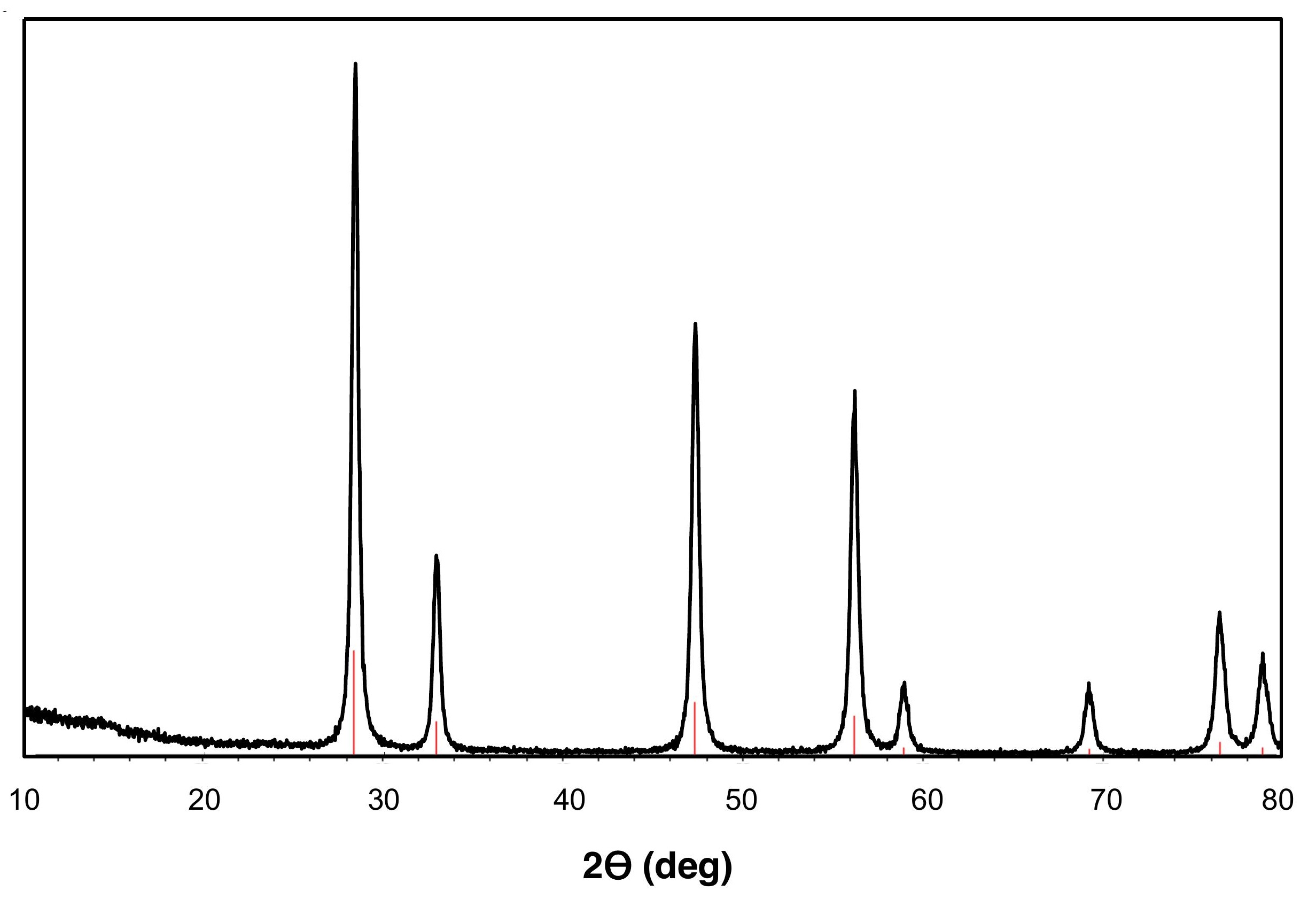




\section{Figure 3}
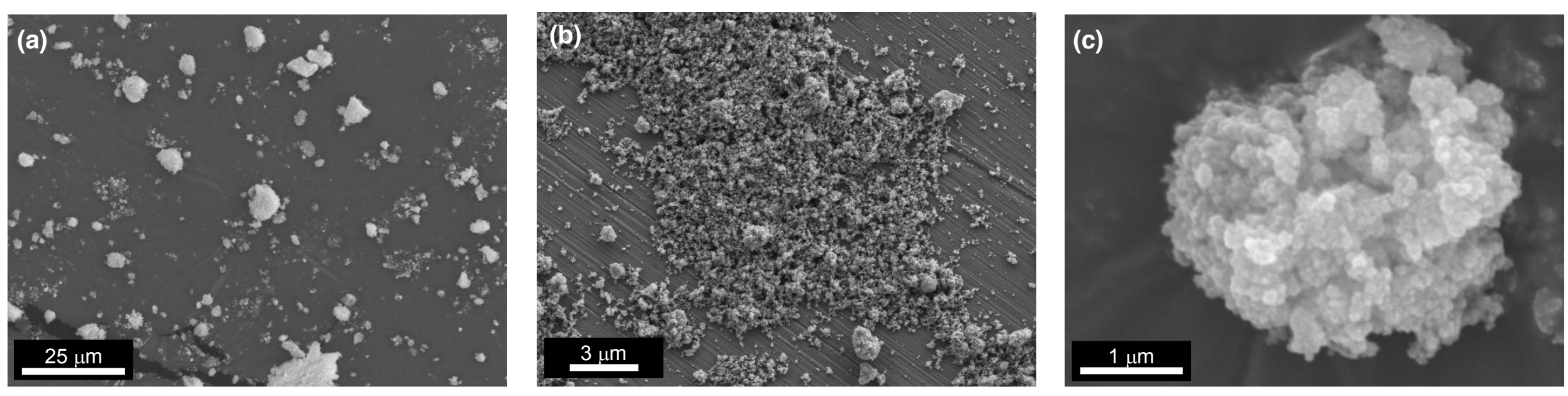


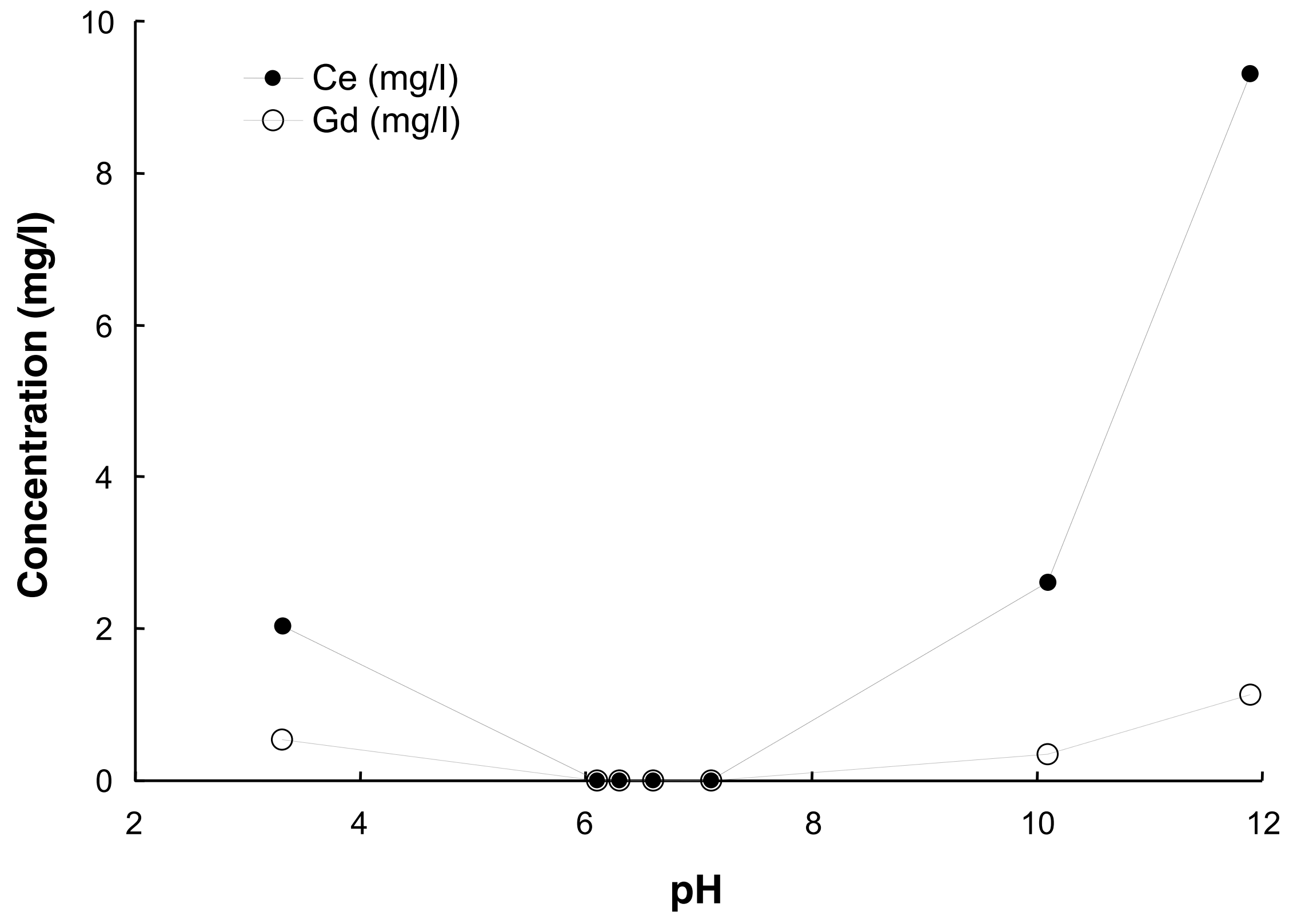


Figure 5

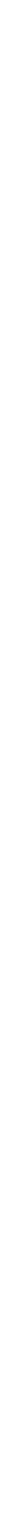




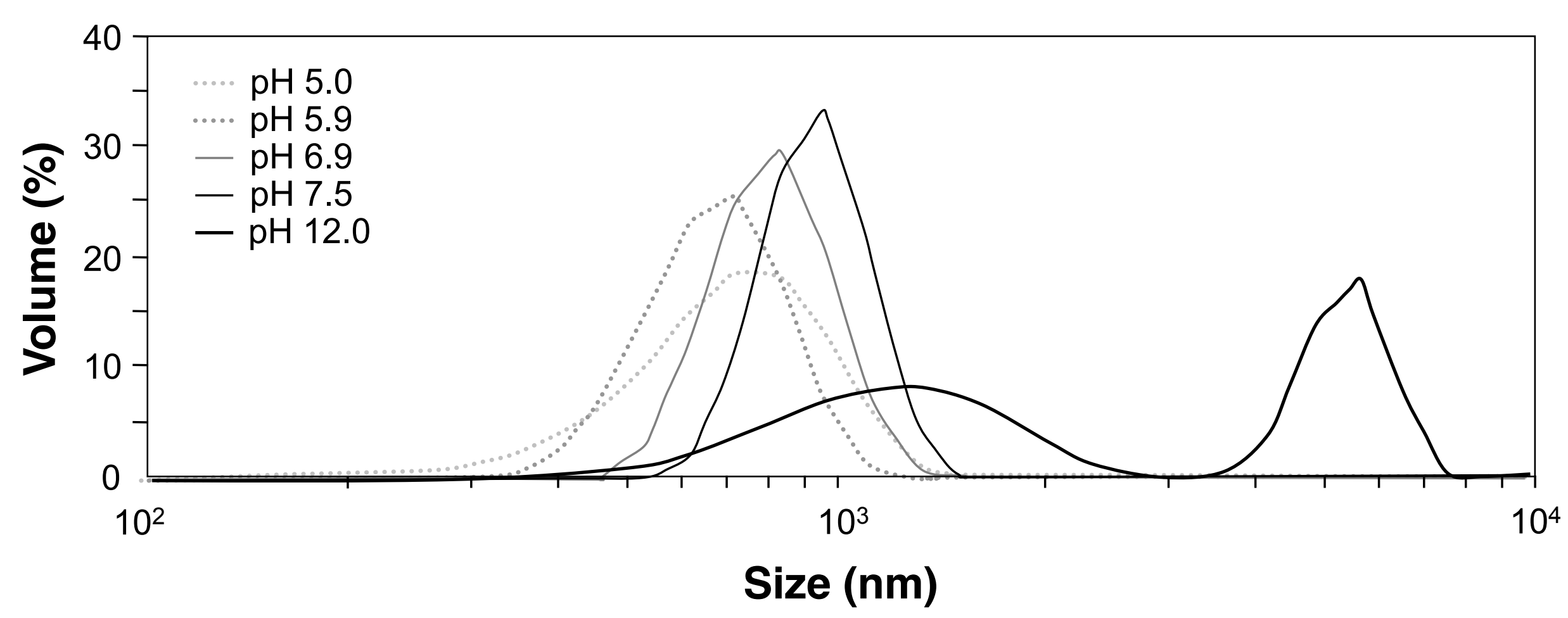




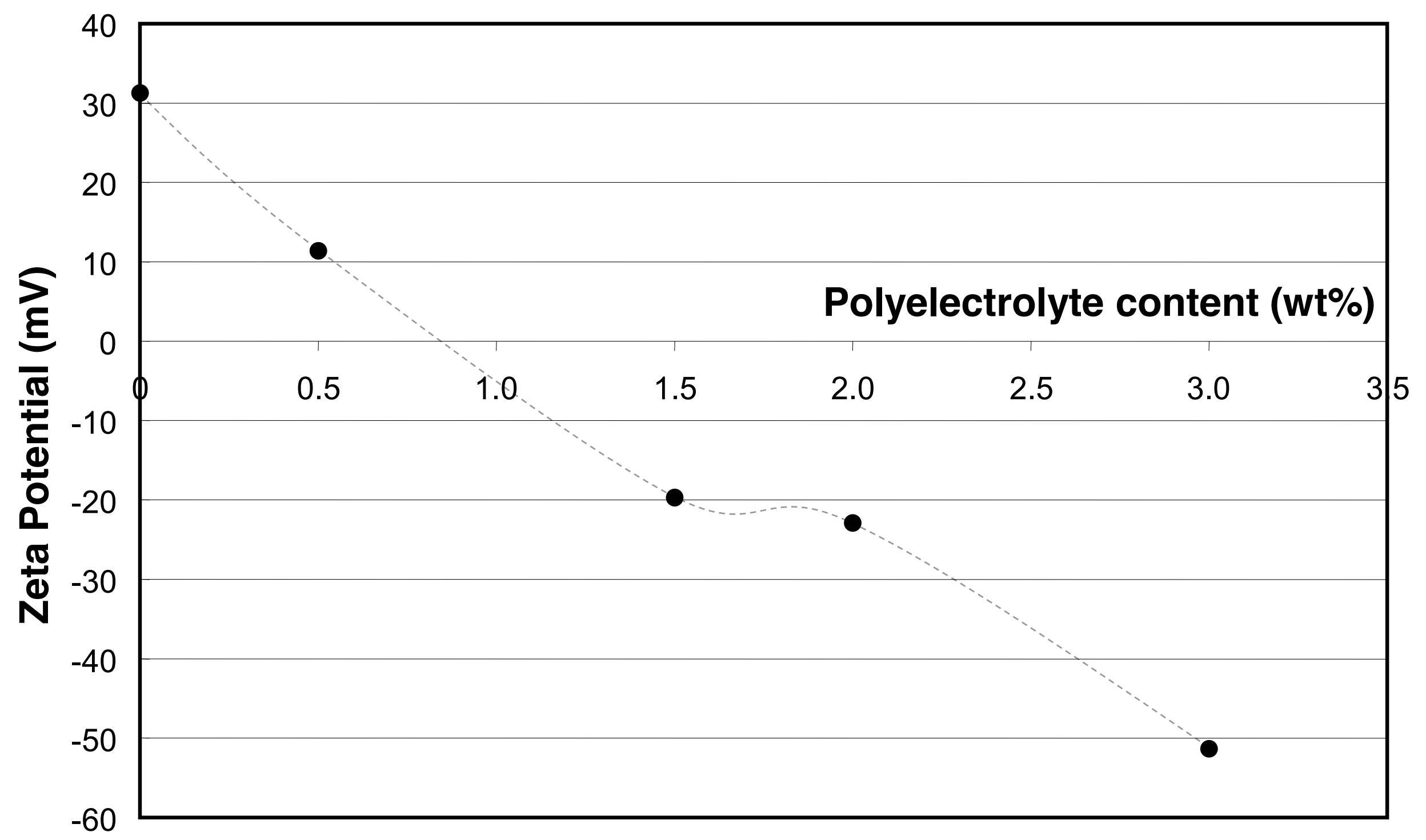




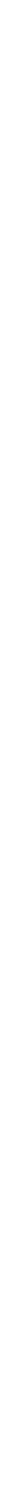




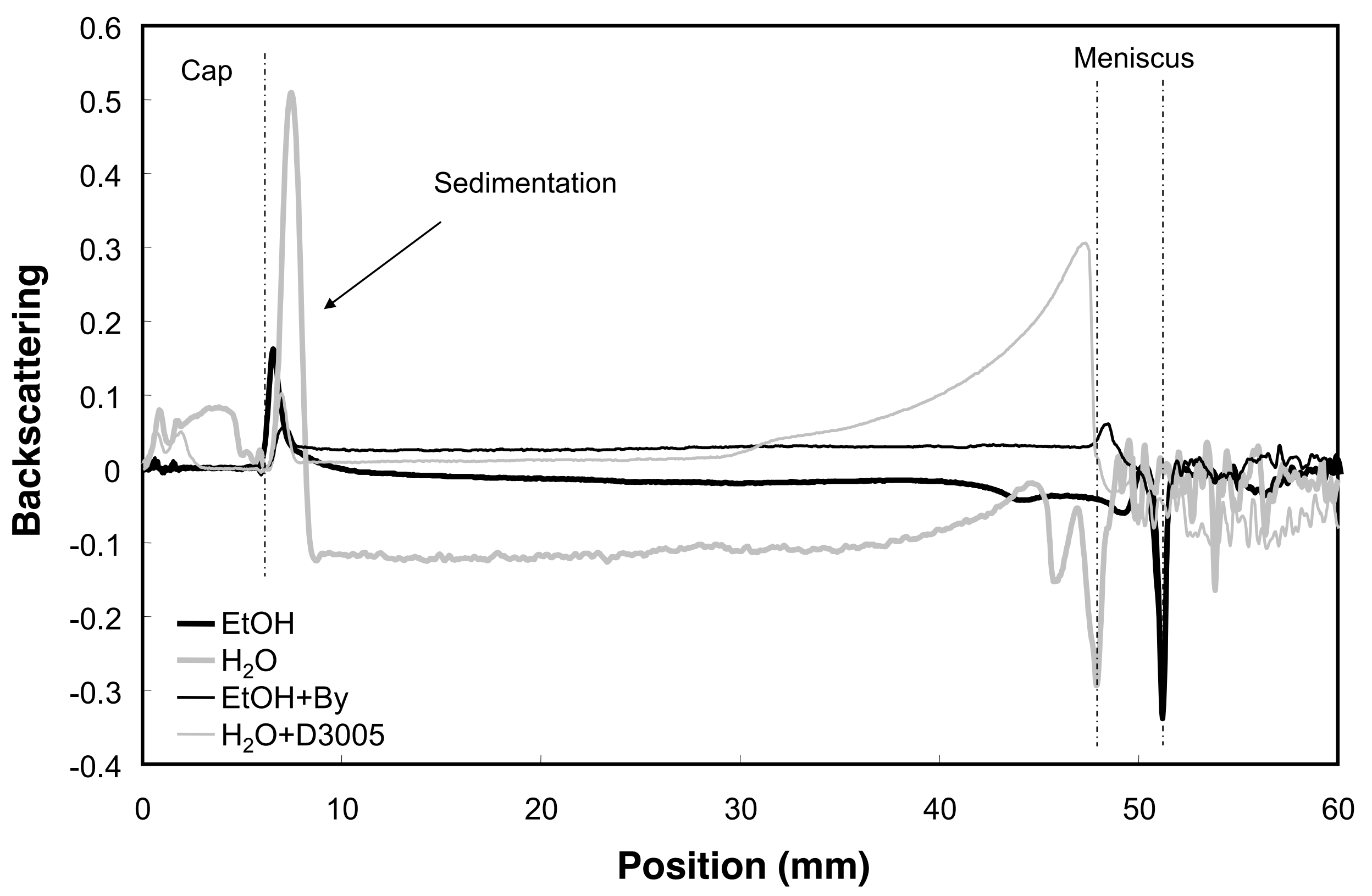




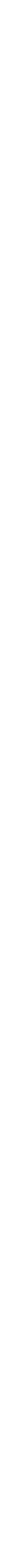


TABLES

\begin{tabular}{ccc}
\hline Suspension & Deflocculant & $\boldsymbol{U}(\mathrm{cm} / \mathrm{s})$ \\
\hline $\mathrm{GDC}$ in $\mathrm{H}_{2} \mathrm{O}$ & - & $1.6 \times 10^{-3}$ \\
\hline $\mathrm{GDC}$ in $\mathrm{EtOH}$ & - & $1.4 \times 10^{-3}$ \\
\hline $\mathrm{GDC}$ in $\mathrm{H}_{2} \mathrm{O}$ & Duramax-D3005 (3.0 wt $\%)$ & $3.2 \times 10^{-4}$ \\
\hline $\mathrm{GDC}$ in $\mathrm{EtOH}$ & Beycostat-C213 (2.0 wt $\%)$ & $2.5 \times 10^{-4}$ \\
\hline
\end{tabular}

Table 1. Values of sedimentation rate for the four suspensions of GDC. 